\title{
A PeRspeCtiva OrganizaCIONAL DE CONTROLE EM UMA ORGANIZAÇÃO PRESTADORA DE SERVIÇOS DA MARINHA DO BRASIL: O CASO CASNAV
}

\author{
The Organizational Perspective of Control in a \\ Rendering Organization of Services of the \\ Brazilian Navy: the case CASNAV
}

Envio 04.10.08 / Aceite 18.11.08

\author{
Ana Carolina Pimentel Duarte da Fonseca ${ }^{1}$ \\ Anderson Soares Silva ${ }^{2}$
}

\section{Resumo}

A Marinha do Brasil (MB), alinhada com as reformas proposta pelo Governo Federal na busca de uma administração pública gerencial, procurou adotar ferramentas que aperfeiçoassem seus processos administrativos em busca de uma melhoria contínua. Nesse sentido, destaca-se a adoção do planejamento estratégico pelas Organizações Militares Prestadores de Serviços (OMPS) da MB. Cabe ressaltar, porém, que o fato destacado traz consigo um aspecto ainda pouco estudado no setor público, que consiste nos sistemas de controle gerencial utilizados por essas organizações, a fim de que os objetivos traçados sejam atingidos. Assim, este trabalho teve por objetivo verificar a relação, em termos de proximidade ou afastamento entre o controle gerencial desenvolvido no Centro de Análises Navais (CASNAV) e os conceitos contidos na abordagem que se refere à perspectiva organizacional de controle, na qual se leva em consideração o desenho de instrumentos, bem como o exercício de ações que estejam direcionadas a influenciar no comportamento das pessoas que fazem parte da organização, para que atuem de acordo

'Doutora em Administração pelo COPPEAD/UFRJ. Professora Adjunta do Programa de Mestrado em Ciências Contábeis da Faculdade de Administração e Ciências Contábeis (FACC/UFRJ). E-mail: anafonseca@pobox.com

${ }^{2}$ Mestre em Ciências Contábeis pela FACC/UFRJ. Encarregado da Seção de Análise Gerencial das Organizações Militares Prestadoras de Serviços Industriais (OMPS-I) da Diretoria de Finanças da Marinha. E-mail: soares@dfm. mar.mil.br 
com os objetivos da administração. Dos resultados encontrados, à luz da literatura existente, foi possível depreender que existe um alinhamento entre teoria e prática, representada pelas ações desenvolvidas pela organização no sentido de influenciar o comportamento de seus componentes.

Palavras-chave: Controle Organizacional; Cultura; Comportamento; Marinha; Resultados.

\begin{abstract}
The Brazilian Navy (BN), lined up with the reforms proposal for the Federal Government in the search of a managemental public administration, looked for to adopt tools that perfected its administrative proceedings in search of a continuous improvement. In this direction, it is distinguished adoption of the strategical planning for the Rendering Military Organizations of Services (RMOS) of the BN. It fits to stand out, however, that the detached fact brings still obtains a aspect little studied in the public sector, that consists of the systems of managemental control used by these organizations so that the objective tracings are reached. Thus, this work had for objective to verify the relation, in terms of proximity or removal, enters the managemental control developed in the CASNAV and the concepts contained in the boarding that if it relates to the organizacional perspective of control, in which if it takes in consideration the drawing of instruments, as well as the exercise of actions that are directed to influence in the behavior of the people who are part of the organization so that the objectives of the administration act in accordance with. of the found results, to the light of existing literature, it was possible to infer that an alignment between practical theory exists and, represented for the actions developed for the organization in the direction to influence the behavior of its components.
\end{abstract}

Keywords: Organizational Control; Culture; Behavior; Navy; Results.

\title{
1 Introdução
}

A partir da criação do sistema das Organizações Militares Prestadoras de Serviços (OMPS), a Marinha do Brasil (MB), alinhada com a agenda de reformas proposta pelo Governo Federal na busca do estabelecimento de uma administração pública gerencial, sempre procurou desenvolver iniciativas e adotar ferramentas que aperfeiçoassem seus processos administrativos em busca de uma melhoria contínua.

Nesse sentido, pode-se destacar a adoção do planejamento estratégico pelas OMPS. A confirmação de tal afirmativa encontra respaldo no trabalho de Pereira (2006, p.2) que afirma:

[...] buscando o desenvolvimento de uma gestão flexível e eficiente, para atender a demanda de uma sociedade mais exigente bem como se adequar ao mundo moderno que requer das organizações uma atitude pró-ativa, a Marinha do Brasil, assim como outros órgãos públicos, incentivou a aplicação do planejamento estratégico como ferramenta de administração, visando aprimorar as práticas administrativas internas.

Cabe ressaltar, porém, que a adoção do planejamento estratégico por parte das OMPS traz consigo um aspecto ainda pouco estudado no setor público, que consiste nos sistemas de

Rev. Adm. UFSM, Santa Maria, v. 2, n. 1, p. 98-115, jan./abr. 2009 
controle gerencial utilizados por essas organizações, a fim de que os objetivos traçados sejam atingidos.

Assim, é possível destacar o trabalho de Gomes (1983) como um dos precursores no Brasil, no que se refere ao estudo do controle gerencial em órgãos estatais, uma vez que a maior parte da literatura sobre o assunto ainda é, até os dias de hoje, voltada para o estudo de organizações componentes da iniciativa privada e com fins lucrativos.

O pensamento acima encontra reflexo em Spiller (1990, p.2):

Cabe destacar que a maior parte dessa literatura é voltada para o estudo de organizações pertencentes ao setor privado e com fins lucrativos, levando, primeiramente, Gomes (1983) a desenvolver seu estudo abordando as empresas estatais, dada a necessidade de investigações sistemáticas que pudessem identificar e explicar as características dos sistemas de controle gerencial existentes nessas empresas [...], como forma de reduzir o desconhecimento sobre o assunto.

Diante do exposto, o presente trabalho, buscando seguir a trilha deixada por Gomes (1983), pesquisou o sistema de controle gerencial de uma organização prestadora de serviços da Marinha, denominada CASNAV.

Com isso, este trabalho tem por objetivo geral verificar a relação, em termos de proximidade ou afastamento, entre o controle organizacional desenvolvido no CASNAV e os conceitos contidos na literatura, no que se refere à perspectiva organizacional de controle. Como objetivo específico, buscou identificar os mecanismos de controle gerencial adotados pelo CASNAV, dentro do contexto organizacional, diante dos bons resultados obtidos pela referida organização, destacando-se as seguidas premiações entre 2004 e 2007 no Prêmio Nacional de Gestão Pública (PQGF).

Para tanto, o artigo foi organizado em estudo de caso, tendo, além desta primeira seção, em que foi realizada a contextualização do tema e a apresentação do sistema OMPS, mais cinco seções. Na seção 2, tratou-se dos aspectos teóricos, com ênfase na perspectiva organizacional do controle gerencial de acordo com Gomes e Salas (1999), por constituir-se na pedra fundamental da pesquisa. Na seção 3, foram abordados os aspectos metodológicos de acordo com os quais a pesquisa foi delineada. Na seção 4 , foi realizada a caracterização do CASNAV, abordando-se aspectos relativos à sua administração. Além disso, buscou-se apresentar de forma aprofundada as características principais do seu contexto organizacional e o detalhamento do seu sistema de controle gerencial. Na seção 5, foi realizada uma análise crítica do sistema de controle gerencial sob a perspectiva organizacional. Por fim, na seção 6, foram formuladas as considerações finais, bem como as recomendações.

\subsection{O Sistema OMPS}

O Sistema OMPS foi implantado no âmbito da Marinha do Brasil (MB) a fim de solucionar a preocupação existente entre a alta Administração Naval quanto à incapacidade de mensuração dos custos das organizações militares industriais e prestadoras de serviços (MARINHA DO BRASIL, 2004b, p.15-1). Tal preocupação encontrava origem, à época, principalmente, nos seguintes fatos: a) constantes déficits financeiros dessas organizações; e b) desconhecimento de outras posições econômico-patrimoniais que possibilitassem a identificação e a correta avaliação das diversas atividades desenvolvidas nestas organizações (MARINHA DO BRASIL, 2004b, p.15-1). 

permitisse:

Diante de tal cenário, percebeu-se a necessidade de criação de um sistema que

a) conhecimento dos gastos efetivos de operação dessas organizações, separados em custos de produção/prestação de serviços e gastos inerentes às atividades administrativas; e b) gerência dos ativos, isto é, domínio perfeito das disponibilidades financeiras, conhecimento dos faturamentos efetuados e da imobilização dos estoques (MARINHA DO BRASIL, 2004b, p.15-1).

Assim, a Marinha criou as Organizações Militares Prestadoras de Serviços (OMPS) e o Sistema OMPS, no ano de 1994, na busca do aprimoramento dos controles internos e da determinação mais eficiente dos custos das organizações militares industriais e prestadoras de serviços (MARINHA DO BRASIL, 2004b, p.15-1).

Conceitualmente, OMPS é a organização militar que presta serviços a outras organizações militares e, eventualmente, a organizações extra-Marinha em uma das seguintes áreas: industrial, de ciência e tecnologia, hospitalar, de abastecimento e de serviços especiais, efetuando a cobrança pelos serviços prestados, a partir dos custos e despesas por ela incorridos (MARINHA DO BRASIL, 2004b, p.15-2). Assim, é possível perceber que, à semelhança das empresas privadas, o relacionamento do tipo "fornecedor x cliente" passou a ser buscado pelas OMPS.

Decorrentes da criação do Sistema OMPS, destacam-se, dentre outros, os seguintes benefícios para a MB: a) evitou-se o fluxo físico de recursos do Fundo Naval (FN) e do Tesouro entre uma OM e uma OMPS, tendo em vista que o pagamento pelos serviços prestados é feito de forma escritural; b) evitou-se a dupla execução dos créditos orçamentários e sua representação no balanço da MB; c) permitiu o conhecimento do custo efetivo de operação de uma OMPS, na forma mais real possível; e d) permitiu uma melhor aplicação dos recursos do FN (MARINHA DO BRASIL, 2004b, p.15-3).

\section{Referencial teórico}

\subsection{Controle gerencial}

Otley, Broadbent e Berry (1995) afirmam que as raízes do controle gerencial encontramse nos primórdios do pensamento administrativo. Os estudos dessa época foram caracterizados por uma atenção aos problemas reais com uma abordagem científica focada na compreensão e no desejo de resolver problemas. Gomes (1999) afirma que a partir da década de setenta, principalmente, pode-se perceber o surgimento de novas abordagens que, valendo-se de uma perspectiva mais ampla do conceito de controle, passaram a incorporar conhecimentos oriundos de outras áreas, como, por exemplo: Psicologia, Sociologia e Antropologia.

Assim, diante da existência de diversas abordagens sobre controle gerencial, neste estudo, foram priorizadas aquelas que enfatizam a importância dos aspectos motivacionais e comportamentais dos sistemas de controle gerencial. Para tanto, tomou-se por base o trabalho de Gomes e Salas (1999), que apresentou algumas das principais abordagens sobre controle gerencial enquadradas no contexto acima. Tais abordagens são representadas pelos trabalhos de Anthony (1965), Flamholtz (1979) e Hofstede (1981). 
Cumpre ressaltar que, dentre as principais abordagens, destaca-se a de Anthony (1965), pois conforme afirma Martinewski (2003, p.26):

Independentemente da forma como o estudo de controle gerencial é sistematizado, parece, entretanto, incontestável que a primeira abordagem que, efetivamente, se tornou referência na área de controle gerencial foi o trabalho de Anthony (1965).

Segundo Anthony e Govindarajan (2002, p. 34), "o controle gerencial é o processo pelo qual os executivos influenciam outros membros da organização, para que obedeçam às estratégias adotadas". Ao fazerem considerações sobre comportamento, os referidos autores destacam que, apesar de sistemático, o processo de controle gerencial não é mecânico, pois envolve interações entre indivíduos. Tal fato justifica-se pela existência dos objetivos pessoais dos executivos e membros da organização em geral.

O problema principal do controle é induzir esses indivíduos a atuarem de maneira que, ao procurarem seus objetivos pessoais, auxiliem o alcance dos objetivos da organização, chegando-se, dessa forma, à chamada congruência de objetivos (ANTHONY e GOVINDARAJAN, 2002). Isso significa que os objetivos individuais do pessoal da organização devem ser consistentes com os objetivos dela própria, na medida do possível. Porém, esses autores destacam a impossibilidade do alcance de uma completa congruência de objetivos, tendo em vista que ela é afetada tanto por processos informais como por sistemas formais, que, por sua vez, influenciam o comportamento humano dentro das organizações.

Os referidos processos informais têm origem externa e interna à organização. Para Anthony e Govindarajan (2002), a maioria deles é de origem interna. Dentre os fatores de origem interna, a cultura da organização é apontada como o mais importante. Para Anthony e Govindarajan (2002), as normas culturais são extremamente importantes, pois explicam por que duas organizações podem ter sistemas formais de controle gerencial iguais, mas uma ter um controle melhor do que a outra.

Merchant (1982, p. 44) afirma que "após estabelecer estratégias e fazer planejamento, a tarefa primária da administração é tomar medidas para assegurar que esses planos sejam implementados".

O plano de referência de Flamholtz (1979), ao mesmo tempo em que enfatiza os aspectos comportamentais dos membros da organização, destaca a incerteza inerente ao processo de controle gerencial. Nesse sentido, ele demonstra que os sistemas de controle são mais probabilísticos do que determinísticos, ou seja, o propósito é maximizar as condições favoráveis que levam ao goal congruence. Nessa abordagem, a motivação de indivíduos ou grupos é o elemento-chave, não se tratando de controlar o comportamento das pessoas de maneira predeterminada, mas influenciá-las a agirem de forma consistente com os objetivos da organização (GOMES e RODRIGUES, 2005).

Otley (1994) afirma que a avaliação de desempenho e o accountability (prestação de contas) ainda são as pedras angulares sobre as quais se baseia um controle gerencial efetivo. Assim, é possível depreender, do pensamento anterior, que o controle gerencial contém princípios aplicáveis ao setor público, principalmente no que diz respeito ao aspecto da prestação de contas, entretanto cabe ressaltar que a ausência do objetivo de lucro leva à necessidade de adaptações dos mecanismos de controle.

Nesse sentido, Hofstede (1981) destaca que as abordagens tradicionais de controle gerencial geralmente falham quando adotadas para empresas públicas ou sem fins lucrativos. Dessa forma, os sistemas de controle gerencial de organizações públicas e sem fins lucrativos 
não podem ser os mesmos desenvolvidos para outras formas de organização, devendo-se observar as peculiaridades inerentes a esse tipo de organização.

\subsubsection{A abordagem de Gomes e Salas (1999)}

Gomes e Salas (1999) afirmam que, nas décadas de oitenta e noventa, foi possível perceber um interesse crescente por parte dos estudiosos quanto ao entendimento da estreita relação existente entre o contexto social e organizacional e o funcionamento da organização e, especialmente, o processo de controle. A literatura tradicional sobre controle de gestão passou a ser criticada, dentre outros, pelos seguintes motivos: a) a consideração de que os objetivos organizacionais representam a congruência dos diferentes interesses dos grupos e pessoas que compõem a organização; b) a consideração de que a contabilidade de gestão é um instrumento técnico, objetivo e neutro no processo de decisão; e c) a consideração de que as deficiências nos sistemas de controle estão centradas em disfunções formais, ignorando os conflitos sociais que existem na organização.

Esses autores afirmam que o controle é necessário para assegurar que as atividades de uma organização se realizem da forma desejada pelos membros da organização e contribuam para o alcance de seus objetivos. Para tanto, a administração deve se assegurar de obter informação e influenciar o comportamento das pessoas, a fim de atuar sobre as variáveis internas e externas de que depende o funcionamento da organização.

O processo de controle requer a obtenção de informação que propicie a formulação de diretrizes, bem como a mensuração do resultado nos mesmos moldes. Tal informação pode fazer referência à evolução do contexto social global, à evolução do setor econômico e à evolução da própria organização. Dessa forma, ao possuir a informação relevante, coletada e selecionada pelo sistema de informações, é possível a tomada de decisões (tentando antecipar o que pode acontecer) e a avaliação do comportamento de cada responsável (análise do que efetivamente ocorreu).

Nesse contexto, o controle pode ser considerado a partir de duas perspectivas: uma perspectiva estratégica e uma perspectiva organizacional. Na primeira, trata-se de facilitar a adaptação estratégica da organização em seu contexto social; na segunda, trata-se de assegurar que toda a organização se oriente conjuntamente na direção dos objetivos da administração.

Partindo-se do atual estágio de desenvolvimento teórico sobre controle gerencial, um sistema de controle gerencial deve considerar três elementos: o sistema de controle propriamente dito, o contexto organizacional e o contexto social.

O sistema de controle propriamente dito compreende a estrutura e o processo de controle. A estrutura refere-se às responsabilidades de cada gestor ou responsável por centros de responsabilidade e compreende três elementos: o sistema de medidas, o sistema de informações e o sistema de incentivos. Já o processo de controle compreende a formulação de objetivos, o orçamento (planejamento e previsão dos meios e custos para o alcance dos objetivos) e a avaliação do desempenho. Integrando o sistema de controle estão: a contabilidade financeira, a contabilidade de gestão (sistema de custos, orçamentos), além de elementos menos formalizados, como a cultura organizacional, o estilo de liderança, a ética, e a ecologia, entre outros. O contexto organizacional compreende: a estrutura da organização, que facilita ou não a coordenação e a eficiência; a estratégia; as pessoas que fazem parte da organização, bem como as relações interpessoais, que favorecem uma maior ou menor motivação; e a cultura organizacional, que favorece uma maior ou menor identificação dos membros da organização com a mesma. 
Finalmente, o contexto social compreende: o mercado, o setor competitivo (clientes, fornecedores e concorrência), o país (valores, instituições, história, nível de desenvolvimento) e a sociedade como um todo, em seus aspectos social, tecnológico, cultural, político, demográfico, ecológico, entre outros. Comparado aos demais elementos integrantes do sistema de controle, é o mais complexo de ser controlado.

Diante do acima exposto e tendo em vista os objetivos a que se propõe a presente pesquisa, a seguir, apresentar-se-ão as principais características da perspectiva organizacional de controle, ainda de acordo com Gomes e Salas (1999).

\subsubsection{Controle organizacional}

Segundo Gomes e Salas (1999), o controle organizacional refere-se ao desenho de instrumentos e ao exercício de ações que estejam direcionadas a influenciar no comportamento das pessoas que fazem parte da organização para que atuem de acordo com os objetivos da administração. Os instrumentos e ações de controle, por sua vez, sofrem a influência de diversos aspectos que, quase sempre, não estão precisamente desenhados e determinados pela administração, tais como a cultura organizacional, o contexto social, entre outros. Tais influências devem ser consideradas quando se busca compreender o comportamento individual e organizacional.

A congruência de objetivos é atingida quando todos os escalões de uma organização trabalham para o bem da empresa como um todo. Existe uma conscientização de que nada adianta determinado setor apresentar um desempenho ótimo, se este benefício não for convertido para todos. É desenvolvida uma mentalidade de diálogo, com o intuito de coordenar as atividades desempenhadas pelos funcionários, para que todos caminhem na direção dos objetivos propostos pelo alto escalão. Isso é mais do que uma simples cooperação.

De acordo com Berry et al. (apud MARTINEWSKI, 2003), um grupo de autores concentrou suas pesquisas especificamente no aspecto social, trazendo a noção de "cultura" para a área da administração. Para esses autores, ressalta Martinewski (2003), a literatura antropológica relevante para controle é bastante diversa; embora todos concordem quanto a sua importância, alguns veem a cultura como uma ferramenta a ser usada pelos administradores. Outros, porém, a veem como uma influência restritiva, principalmente em situações de mudança. Isto significa que uma determinada cultura pode ser um controle útil em situações em que não ocorram mudanças; quando uma mudança é necessária, ela somente não será problemática quando não afetar a cultura existente, tal pensamento encontra-se relacionado com a abordagem de Smircich (1983).

Smircich (1983, p.347) aponta como duas as principais tendências que balizam o estudo sobre cultura organizacional. A primeira delas é a perspectiva funcionalista, que enfoca a cultura organizacional como uma variável, "algo que a organização tem". A segunda tendência, segundo a referida autora, é a da tradição fenomenológica, que entende a cultura como "algo que a organização é".

Para os defensores da primeira corrente de pensamento, a cultura é incorporada ao próprio conceito de controle, permitindo a integração da organização e aumentando a probabilidade de que o comportamento individual e organizacional se dirija ao alcance dos objetivos. Dessa forma, para esta corrente, é necessário que o desenho e a implantação de uma contabilidade de gestão sejam realizados em função dos aspectos técnicos e do contexto organizacional, entre os quais se encontra a cultura organizacional (GOMES e SALAS, 1999). 
Já de acordo com a segunda corrente, segundo Gomes e Salas (1999, p.37), "a contabilidade de gestão não é simplesmente um artefato técnico cuja introdução facilita o alcance da eficácia organizacional, mas que também cria determinados significados subjetivos e percepções que surgem da contínua interação social entre os indivíduos". Nesta corrente, o sistema de controle tem caráter simbólico podendo desempenhar papel importante na criação de valores dentro da organização. Assim, outorga-se importância especial aos processos de controle por meio dos quais se descobre, valoriza e compartilha diferentes objetivos e preferências por parte dos membros da organização (GOMES e SALAS, 1999).

Gomes e Salas (1999) apontam que a maior parte das contribuições da perspectiva cultural do controle parece concordar com o fato da contabilidade de gestão estar integrada dentro de um sistema organizacional mais amplo que o dos aspectos formais e psicossociais, e que compreende os valores da organização. Em consequência disso, o desenho e utilização de um sistema de controle devem incorporar uma maior compreensão dos valores organizacionais.

Ao definirem cultura, em seu sentido mais amplo, Gomes e Salas (1999, p. 35) afirmam que esta pode ser vista "como um mecanismo de depuração (filtro) que reflete o meio ambiente e que, quando combinado com personalidade, estabelece premissas de ação e decisões para os indivíduos dentro de um determinado grupo cultural".

Segundo Schein (1992, p. 12), a cultura organizacional é "o conjunto dos pressupostos básicos que determinado grupo tem inventado, descoberto ou desenvolvido no processo de aprendizagem para lidar com os problemas de adaptação externa e integração interna". Dessa forma, uma vez que os pressupostos tenham funcionado bem o suficiente para serem considerados válidos, são ensinados aos demais membros como a maneira correta para se perceber, se pensar e se sentir em relação àqueles problemas.

Diante do exposto, Gomes e Salas (1999) afirmam que estudos mais recentes na área de controle de gestão têm focado sua atenção nos mecanismos culturais utilizados pelas organizações para compensar as prováveis limitações dos sistemas de controle.

\section{Metodologia}

Kerlinger (1980) afirma que a natureza, ou seja, o delineamento da pesquisa pode ser definido como sendo o plano e a estrutura da investigação, concebido de forma a obterem-se respostas para as perguntas de pesquisa.

Assim, diante da existência de várias taxonomias de tipos de pesquisa, no presente trabalho será adotada a de Vergara (2003) que propõe classificar as pesquisas quanto aos fins pretendidos e quanto aos meios propostos. A mesma autora observa, ainda, que os tipos de pesquisa "não são mutuamente excludentes", sendo possível utilizá-los de forma combinada (VERGARA, 2003, p.49).

Diante do exposto, pode-se classificar a presente pesquisa como exploratória e descritiva quanto aos fins. Exploratória porque visou buscar a identificação da aplicação de sistemas de controle gerencial em uma organização militar prestadora de serviços do setor público federal, tendo em vista que há pouco conhecimento acumulado nessa área. Descritiva porque buscou expor as características administrativas empregadas na gestão da OMPS, em especial aquelas que se referem ao controle gerencial.

A investigação exploratória, segundo Vergara (2003, p.47), "é realizada em área na qual há pouco conhecimento acumulado e sistematizado". De acordo com Gil (1996), as pesquisas exploratórias possuem por objetivo principal propiciar maior intimidade com o problema. 
Vergara (2003, p. 47) afirma que a pesquisa descritiva consiste em expor as características de uma determinada população ou de determinado fenômeno, podendo estabelecer correlações entre variáveis e definir sua natureza e que a pesquisa descritiva "não tem compromisso de explicar os fenômenos que descreve, embora sirva de base para tal explicação".

Quanto aos meios, trata-se de uma pesquisa bibliográfica, documental e de campo, utilizando-se o estudo de caso como estratégia de pesquisa, de acordo com Yin (2001). Bibliográfica, tendo em vista a importância da sua fundamentação teórica, que tomou por base importantes obras cujo reconhecimento se dá pelo notório saber de seus autores. Documental e de campo, porque envolveu a coleta de dados primários no âmbito da organização estudada, por meio da análise de documentos internos não acessíveis ao público em geral; da aplicação de questionário confeccionado com o objetivo de possibilitar a confrontação do sistema de controle gerencial da OMPS, sob a perspectiva organizacional, com o plano de referência definido na literatura e da observação não-participante. Estudo de caso porque concentra esforços na análise de apenas uma organização, na busca por um maior grau de aprofundamento sobre o assunto.

A pesquisa bibliográfica consiste no estudo sistematizado desenvolvido com base em material acessível ao público em geral, como livros, revistas e jornais, enquanto a investigação documental é feita em documentos conservados no interior de órgãos públicos ou privados de qualquer natureza, ou com pessoas. A pesquisa de campo consiste na investigação empírica realizada no local onde ocorre ou ocorreu um fenômeno ou onde estão disponíveis os elementos para explicá-lo (VERGARA, 2003).

O estudo de caso, afirma Vergara (2003, p.49), "é o circunscrito a uma ou poucas unidades, entendidas essas como pessoa, família, produto, empresa, órgão público, comunidade ou mesmo país".

Segundo Yin (2001, p.21),

o estudo de caso permite uma investigação para se preservar as características holísticas e significativas dos eventos da vida real - tais como ciclos de vida individuais, processos organizacionais e administrativos, mudanças ocorridas em regiões urbanas, relações internacionais e a maturação de alguns setores.

A entrevista foi realizada com o auxílio de um questionário, composto por perguntas abertas, que possibilitou a sistematização das respostas. As perguntas do questionário referem-se ao sistema de controle gerencial projetado pela organização, dentro do contexto organizacional, e o processo por ela desenvolvido, visando à descrição do sistema implantado. O entrevistado é militar, do sexo masculino, com 67 anos de idade. Tendo servido no CASNAV por mais de uma vez, em períodos distintos, perfaz um tempo total de organização de 13 anos. Possuindo formação acadêmica na área de estatística, em nível de mestrado, o referido militar é lotado na assessoria de Ciência e Tecnologia, sendo componente do nível estratégico da organização.

$\mathrm{Na}$ observação não-participante, o pesquisador afigura-se, somente, como um espectador atento a um grupo observado, sendo guiado pelos objetivos da pesquisa e procurando registrar o máximo de ocorrências que convém ao seu trabalho (RICHARDSON, 1989). Cabe destacar que a observação não-participante foi facilitada em grande parte pelo fato de um dos pesquisadores ser Oficial da Marinha, fato que veio a propiciar de forma completa o seu acesso à toda a organização, sem influenciar no andamento do dia-a-dia da mesma. 


\section{Descrição do caso CASNAV}

\subsection{Caracterização da organização}

O Centro de Análises de Sistemas Navais (CASNAV) é uma organização militar prestadora de serviços da Marinha do Brasil, integrante do Sistema de Ciência e Tecnologia da Marinha, tendo sido reconhecido como órgão da área de Ciência e Tecnologia da Administração Pública Federal Direta, em 1993.

No ano de 2001, o CASNAV assinou com a Secretaria Geral da Marinha (SGM), representante legal do Comando da Marinha, o seu primeiro contrato de gestão que, no âmbito da MB, foi denominado Contrato de Autonomia de Gestão (CAG).

Uma das metas contidas no referido contrato era a participação da organização no Prêmio Nacional de Gestão Pública (PQGF) do Governo Federal, fato este que vem ocorrendo desde o ano de 2003. Cumpre ressaltar que o CASNAV foi laureado com premiações, na faixa bronze do referido concurso nos ciclos 2004, 2005 e 2007, não tendo sido em 2006 pelo fato de que o regulamento do PQGF impede que a mesma organização seja premiada na mesma faixa por três anos consecutivos.

Além dos resultados acima mencionados, cabe destacar que a organização alcançou, no mesmo período, uma média de $87 \%$ das metas estabelecidas no CAG.

\subsection{Controle organizacional no CASNAV}

A administração do CASNAV é dividida em três níveis. O primeiro nível é o estratégico, composto pelo diretor, vice-diretor, assessores da direção e chefes dos departamentos, respectivamente, de administração, de engenharia de sistemas e de apoio tecnológico. O segundo nível é o tático, composto pelos encarregados de divisão e assessores dos chefes de departamento. O terceiro nível é o operacional, composto pelos gerentes de projeto e encarregados de seção. As atribuições e responsabilidades de cada função estão definidas no regimento interno da organização e nas demais normas internas pertinentes a cada área, que regulam grande parte dos processos relacionados ao pessoal.

Além disso, existem três conselhos e um comitê com atribuições e componentes formalmente previstos, que participam diretamente do processo de tomada de decisão, assessorando o diretor, autoridade máxima da organização, nos assuntos que lhes couberem. O Conselho Consultivo (ConSult) trata, principalmente, dos assuntos relativos ao Contrato de Gestão. O Conselho Técnico (ConsTec) cuida dos assuntos de natureza técnica. O Conselho Econômico (ConsEco) trata de gerência econômico-financeira. Por fim, o Comitê de Qualidade é responsável pelo bom funcionamento do Sistema de Gestão da Qualidade (SGQ).

O processo decisório da organização é descentralizado, com delegação de poderes autorizada pelo regimento interno e concretizada por meio de ordens internas ou portarias do diretor, nos níveis estratégico, tático e operacional, alinhadas nos três níveis. Assim, as decisões estratégicas cabem à alta administração, composta por todos os membros do nível estratégico; as decisões táticas cabem aos encarregados de divisão e as decisões operacionais são tomadas pelos gerentes de projeto e encarregados de seção.

O CASNAV busca, por meio dos conselhos criados numa administração participativa, o comprometimento das partes interessadas no processo decisório e o maior envolvimento e motivação possíveis dos membros da organização. Dessa forma, segundo o entrevistado, os conselhos servem como elementos de ligação entre os diversos setores e a alta administração. 
No Quadro 1, é possível verificar a participação dos citados conselhos e comitê no processo decisório do CASNAV.

\begin{tabular}{|c|c|c|c|}
\hline CONSELHOS & ATRIBUIÇÃO & COMPONENTES & $\begin{array}{l}\text { PERIODICIDADE } \\
\text { DA REUNIÃO }\end{array}$ \\
\hline Conselho Consultivo & $\begin{array}{l}\text { Assessorar o Diretor nos assuntos } \\
\text { relativos ao CAG, incluindo sua } \\
\text { negociação; orientar a elaboração do } \\
\text { PE e planos decorrentes. }\end{array}$ & $\begin{array}{l}\text { Diretor, Vice-Diretor, Chefes } \\
\text { de Departamento, Assessor- } \\
\text { Chefe de Gestão } \\
\text { Contemporânea e assessores } \\
\text { convocados quando } \\
\text { necessário. }\end{array}$ & $\begin{array}{l}\text { Mensal ou quando } \\
\text { convocado. }\end{array}$ \\
\hline Conselho Técnico & $\begin{array}{l}\text { Apreciar e opinar sobre assuntos de } \\
\text { natureza técnica; e assessorar o } \\
\text { Diretor na coordenação das atividades } \\
\text { técnicas dos Departamentos. }\end{array}$ & $\begin{array}{l}\text { Diretor, Vice-Diretor, Chefes } \\
\text { de Departamento, } \\
\text { Encarregados de Divisão do } \\
\text { Departamento de Engenharia } \\
\text { de Sistemas, Encarregado da } \\
\text { Divisão de Capacitação. }\end{array}$ & $\begin{array}{l}\text { Mensal ou quando } \\
\text { convocado. }\end{array}$ \\
\hline Conselho Econômico & $\begin{array}{l}\text { Assessorar o Vice-Diretor na gerência } \\
\text { econômico-financeira, mediante o } \\
\text { planejamento, a programação, o } \\
\text { controle e a fiscalização dos recursos } \\
\text { orçamentários, financeiros e } \\
\text { patrimoniais. }\end{array}$ & $\begin{array}{l}\text { Vice-Diretor, Ordenador de } \\
\text { Despesa, Agente Fiscal, } \\
\text { Chefes de Departamento, } \\
\text { Gestor da Caixa de } \\
\text { Economias, Gestor da } \\
\text { Execução Financeira, Cestor } \\
\text { de Material. }\end{array}$ & Mensal. \\
\hline Comitê da Qualidade & $\begin{array}{l}\text { Traçar políticas; analisar, criticar, } \\
\text { aprovar e propor ações corretivas/ } \\
\text { preventivas; deliberar sobre } \\
\text { prioridades; assegurar o bom } \\
\text { funcionamento do SGQ; e indicar os } \\
\text { Promotores da Qualidade. }\end{array}$ & $\begin{array}{l}\text { Diretor, membros da Alta } \\
\text { Direção e da tripulaçãao } \\
\text { designados por Ordem de } \\
\text { Serviço. }\end{array}$ & $\begin{array}{l}\text { Semestral ou quando } \\
\text { convocado. }\end{array}$ \\
\hline
\end{tabular}

Fonte: Relatório de Gestão do CASNAV - Ciclo 2007.

Quadro 1 - Processo participativo de tomada de decisões.

O CASNAV almeja a obtenção de metas de alto desempenho mediante a promoção da cultura da excelência na organização, baseada na sua política de qualidade. Assim, a qualidade pode ser apontada como uma das pedras basilares da cultura organizacional, em que merece destaque a figura dos "promotores de qualidade". Tais elementos são selecionados entre os componentes da organização, voluntários, que possuam como características, dentre outras: liderança, entusiasmo, disciplina, visão sistêmica, credibilidade, participação e preocupação com resultados. Os "promotores de qualidade", ao disseminarem conceitos e ideias de qualidade em toda a organização, atuam como os principais agentes de mudança, incentivando o comprometimento de todos com a cultura da excelência.

Nesse sentido, o processo de comunicação interna é visto como uma das bases para a motivação ao comprometimento de todos com a cultura de excelência. Como exemplo, segundo o entrevistado, pode-se citar as palestras realizadas pelo diretor a toda organização, no intuito de reforçar a necessidade do comprometimento com a excelência, além de mostrar os resultados decorrentes da adoção de práticas voltadas para a melhoria contínua. As citadas palestras são realizadas ao final de cada ano, e nelas são apresentados os principais resultados alcançados pelo CASNAV, os óbices encontrados para a consecução, as medidas corretivas adotadas, além das perspectivas para o ano seguinte.

O trabalho em equipe, nos seus diversos níveis, faz parte da cultura do CASNAV, liderado pelos chefes de departamento, encarregados de divisão ou gerentes de projeto. Dessa maneira, é possível formar equipes interdisciplinares, conforme a demanda específica. 
O CASNAV possui valores e tradições peculiares ao meio naval e, além dos valores da Marinha do Brasil, que são estabelecidos em norma específica, a organização decidiu efetuar um complemento, criando um código de ética específico para o seu ambiente interno. Segundo o entrevistado, o CASNAV entende que os valores servem como filtros que impedem que hábitos inadequados se incorporem à cultura da organização ou de parte dela. Assim, o que se deseja é que os componentes da organização ajam de acordo com um mesmo código de valores, que darão o tom comportamental de todos.

Dentre o conjunto de valores que compõem o código de ética do CASNAV, destacamse: a) ética, b) cooperação, c) constância de propósitos, d) fidelidade e e) profissionalismo. Ressalta-se que o entendimento desses valores está formalmente exposto no código de ética da organização.

O CASNAV mede e avalia o bem-estar, a satisfação e a motivação das pessoas por meio da Pesquisa de Clima Organizacional (PCO), que é realizada anualmente por consultoria independente. Nessa pesquisa, vários aspectos são abordados e, dentre outros, destacam-se os seguintes: a) colaboração entre as diferentes áreas, b) relacionamento com as chefias superiores, c) conhecimento sobre as funções, d) relacionamento com colegas de trabalho e e) realização pelos resultados alcançados.

Ressalta-se que o entrevistado destacou, de maneira espontânea, a influência da cultura da organização no comportamento dos indivíduos ao citar que, em certa ocasião, o Diretor do CASNAV, autoridade máxima da organização, logo após tomar posse, comentou sobre o esforço que realizava a fim de se adaptar ao estilo de liderança participativa adotado na organização. Tal situação decorria do fato de que esse Oficial-General, até então, havia vivenciado a Marinha, praticamente durante toda a sua carreira, no setor operativo, onde, por questões doutrinárias, a liderança exercida, normalmente, é de natureza autocrática. Esse relato, na visão do entrevistado, demonstra de forma clara que, independentemente da posição hierárquica, os membros do CASNAV sofrem influência direta da sua cultura, comprovando-se, assim, a sua força.

O sistema de liderança do CASNAV atua segundo uma organização matricial por gestão de projetos, funcionando por num modelo de liderança participativa por meio dos conselhos, sendo sua gestão apoiada pela tecnologia da informação. O CASNAV, por ser ao mesmo tempo uma organização militar e um centro de Ciência e Tecnologia, aprendeu, ao longo dos anos, a balancear de forma harmônica as características da liderança militar, fundamentada na hierarquia e na disciplina e da liderança típica das equipes de pesquisa, pautada principalmente na competência técnica e no esforço cooperativo (CASNAV, 2006).

Assim, o estilo de liderança é o participativo (ou democrático), selecionado como o mais apropriado entre os apresentados pela Doutrina de Liderança da Marinha, tendo em vista que nesse estilo: "abre-se mão de parte da autoridade formal em prol de uma esperada participação dos subordinados e aproveitamento de suas ideias" (MARINHA DO BRASIL, 2004a, p. 1-4).

Segundo o entrevistado, por ocasião da definição da missão da organização, foram levados em consideração fatores como: a força propulsora do CASNAV, o diferencial da organização e os valores disseminados pela organização, já descritos anteriormente. Nesse sentido, a força propulsora do CASNAV seria o componente capaz de alavancar, de forma consistente, a organização, sendo composta por categorias como: a) domínio de técnicas específicas da capacitação, b) domínio das técnicas gerenciais, e c) disponibilização de recursos (materiais e humanos). 
Dentre as características identificadas como o diferencial da organização, destacamse as seguintes: a) qualidade reconhecida, b) imagem positiva dentro e fora da Marinha, c) compromisso com resultados, d) qualificação do corpo técnico e e) qualidade na organização de eventos científicos, tais como simpósios e palestras.

Por fim, cabe destacar que participam da definição da missão, além da alta direção, diversos membros, militares e civis, de escalões intermediários, conforme mencionado pelo entrevistado. Igualmente importante, de acordo com o entrevistado, é que a missão foi revisada e alterada por ocasião da assinatura do CAG, no ano de 2001, diante da revisão das competências básicas da organização que levaram à alteração das tarefas do CASNAV.

Cabe ressaltar que, na Marinha, a missão é declarada por meio da união de dois fatores, que são: o propósito a atingir e as tarefas a desempenhar para atingir tal propósito. Assim, o CASNAV tem o propósito de contribuir para o aprimoramento do processo decisório e do emprego de meios e sistemas da Marinha. Para a consecução de seu propósito, foram atribuídas ao CASNAV as seguintes tarefas, dentre outras: a) realizar a avaliação operacional de sistemas e meios navais, b) pesquisar e desenvolver procedimentos e táticas de emprego para os sistemas e meios navais, c) projetar e desenvolver sistemas de informação para apoio à decisão e d) prestar assessoria técnica para a tomada de decisão aos diversos níveis de direção da MB.

Dentre os fatores-chave para o cumprimento de sua missão, o CASNAV considera a gestão das informações como fator de fundamental importância para o alcance dos objetivos estratégicos da organização, de acordo com a opinião do entrevistado. Nesse sentido, o critério para a seleção das informações baseia-se nas necessidades técnicas e administrativas da organização, e as informações estão categorizadas, conforme sua natureza, em: gestão administrativa, de produção, de apoio tecnológico e contemporâneo.

O CASNAV busca identificar clientes em potencial e estabelecer, com os já clientes, um relacionamento duradouro e proveitoso, criando, com isso, oportunidades de manter um volume contínuo e crescente de negócios. Para tanto, a antecipação às novas tendências de mercado, aos novos cenários, aos desenvolvimentos tecnológicos e aos requisitos legais, é primordial. Assim, a organização privilegia participação do seu pessoal em eventos científicos, além da realização de pesquisa de trabalhos científicos, vistos como as principais fontes de informações e de oportunidades que possibilitam identificar as tendências dos serviços relevantes para os clientes atuais e potenciais.

A avaliação dos resultados obtidos, a partir dos objetivos fixados, é feita através de um sistema de medição estruturado em indicadores de desempenho estabelecidos em consonância com os objetivos estratégicos. Tal sistema constitui-se em uma ferramenta de análise crítica do desempenho global da organização, aplicada em todos os níveis gerenciais e voltada para os resultados. Para isso, foi estabelecido um conjunto de indicadores de desempenho, com a participação da alta administração, dos encarregados de divisão, das assessorias e dos gerentes de projeto, que estão agregados segundo as funções estratégicas da organização.

Por fim, o acompanhamento contínuo dos indicadores estabelecidos para a medição de desempenho, por meio da análise realizada pelos conselhos e comitê, dentro de suas respectivas áreas jurisdicionais, permite que o sistema de controle gerencial do CASNAV sofra uma mudança contínua na busca de sua adequação às mudanças, sejam elas internas ou externas, de acordo o entrevistado. 


\section{Análise dos resultados}

$\mathrm{Na}$ análise dos resultados encontrados, verifica-se que a organização estudada faz uso de diversos mecanismos e desenvolve várias ações com o propósito de exercer o controle organizacional. Assim, no que se refere ao sistema de controle gerencial do CASNAV sob a perspectiva organizacional, à luz da abordagem de Gomes e Salas (1999), é possível depreender que existe um alinhamento entre teoria, representada pela citada obra, e prática, representada pelas ações desenvolvidas pela organização no sentido de influenciar o comportamento de seus componentes.

A afirmação anterior toma forma mais nítida ao considerarmos que, para Gomes e Salas (1999), o controle organizacional refere-se ao desenho de instrumentos e ao exercício de ações que estejam direcionadas a influenciar o comportamento das pessoas que fazem parte da organização, a fim de que as atuem de acordo com os objetivos da administração. Da mesma forma, os citados autores destacam que os instrumentos e ações de controle sofrem a influência de diversos aspectos, tais como: a cultura organizacional, o contexto social, entre outros, e que tais influências devem ser consideradas quando se busca compreender o comportamento individual e organizacional. Diante disso, pode-se afirmar que os mecanismos e as ações que compõem o sistema de controle do CASNAV apontam para o estabelecimento de uma cultura orientada para a excelência, como forma de se cumprir os objetivos da organização.

Tal fato encontra-se em ressonância com o pensamento de Anthony e Govindarajan (2002) ao apontarem a cultura organizacional como o fator interno, informal, que possui maior importância no processo de controle gerencial de uma organização.

Dentre os referidos instrumentos, destacam-se: os indicadores de desempenho, os sistemas de informação, os "promotores de qualidade", investimento no capital humano, ênfase nos valores da organização e mensuração do clima organizacional.

Nesse sentido, a divisão da estrutura organizacional em níveis estratégico, tático e operacional; bem como o estabelecimento dos Conselhos Consultivo, Técnico e Econômico, além do Comitê de Qualidade, contribuem para facilitar a coordenação dos diversos setores da organização, servindo de elo entre estes e a alta administração e permitindo uma gestão de caráter participativo, na qual se busca o maior comprometimento possível das pessoas com os objetivos organizacionais.

Vale mencionar que o estabelecimento dos Conselhos Consultivo, Técnico e Econômico, além do Comitê de Qualidade na administração da organização, aponta para um tipo de controle técnico em que o controle das atividades é confiado a especialistas, segundo a classificação de Hofstede (1981), corroborando, mais uma vez, com as características da cultura da organização, que é um reconhecido centro de excelência na área de ciência e tecnologia.

A medida de desempenho global da organização, à luz do contrato de gestão, com ênfase na qualidade e na produtividade, demonstra a intenção de atender às demandas do contexto social externo, tendo em vista ser o CASNAV um órgão público, bem como a de reforçar a cultura de excelência voltada para resultados de alto desempenho. Tal fato encontrase em acordo com o que preconizam Gomes e Salas (1999) ao apontarem a necessidade de vinculação do sistema de controle com a estratégia, bem como com os aspectos culturais.

Isso se confirma pelo desenho do quadro de indicadores de controle, que é fortemente influenciado pelo contexto cultural e por aspectos não financeiros, de acordo com o pensamento de Hofstede (1981), em que o referido autor afirma que os sistemas de controle gerencial de organizações públicas devem ser específicos para tal atividade, devendo-se evitar a adoção das abordagens tradicionais, uma vez que estas, por focarem as organizações com fins lucrativos, 
normalmente falham em órgãos públicos. Por esse motivo, os sistemas de informação do CASNAV apresentam outros tipos de informação, além das tradicionais informações financeiras.

Dentre os sistemas de informação, destaca-se o Sistema de Gestão da Qualidade (SGQ), estruturado para atender aos critérios de excelência do Programa de Qualidade do Serviço Público. O referido sistema configura-se, na verdade, como uma das principais ferramentas de promoção da cultura de excelência dentro da organização, contribuindo para a solidificação da política de qualidade adotada pelo CASNAV, a partir do ano de 2001.

Nesse ponto, é possível visualizar um estreitamento de relação entre o posicionamento da organização e o pensamento de Merchant (1982) ao afirmar que, após estabelecer estratégias e planos, a tarefa primária da administração é tomar medidas para assegurar que os mesmos sejam implementados. Isso se dá pelo fato de que ao optar pelo desenvolvimento de uma política de qualidade, o CASNAV envidou esforços, principalmente através do SGQ, no sentido de assegurar que a referida política fosse efetivamente implantada.

Outro mecanismo que merece destaque é o uso dos "promotores de qualidade", que cumprem papel de vital importância, uma vez que atuam como os principais agentes de mudança, incentivando o comprometimento de todos com a cultura de excelência, configurando-se, dessa forma, como os catalisadores do processo de qualidade da organização. Com isso, pode-se depreender, de forma mais nítida, a intenção da alta administração do CASNAV de exercer o controle por meio da influência cultural, fato este que guarda estreita relação com Gomes e Salas (1999), que afirmam que várias pesquisas têm demonstrado que os membros de uma organização tendem a repetir os comportamentos que são valorizados positivamente, por meio da aprovação do comportamento pelos superiores hierárquicos.

O investimento na capacitação de seus servidores, além de constituir-se em mais uma das ferramentas na busca pela excelência nos serviços prestados, também pode ser apontado como um meio encontrado pela organização para o alcance do goal congruence, de acordo com o pensamento de Gomes e Salas (1999). Isto se dá, tendo em vista que ao realizar um curso de pós-graduação, por exemplo, o servidor sente-se prestigiado ao ver que a organização está atenta aos seus interesses individuais. Em contrapartida, essa pessoa, devidamente motivada e comprometida com a organização, empenha-se em atender àquilo que dela se espera em termos organizacionais.

De acordo com Gomes e Salas (1999, p.126), o comportamento adequado, por parte dos membros de uma organização, "pode orientar-se com maior probabilidade de acerto na direção dos objetivos globais, à medida que se estimule sua motivação e identificação com os interesses individuais ou de grupos responsáveis pelas decisões, nos mais diversos níveis hierárquicos".

Ao afirmar que os valores podem servir como filtros que impedem hábitos inadequados, bem como empregar vários mecanismos que visam à solidificação dos valores da organização, 0 CASNAV aponta para a importância dada à cultura organizacional como meio de comprometer as pessoas com os objetivos e metas institucionais.

Nesse sentido, a realização da PCO vem a confirmar a relevância dada pela alta administração à manutenção de uma cultura interna forte, servindo como pilar para a existência de comportamentos compatíveis com o desejado. Assim, ao monitorar o clima organizacional, por meio da PCO, o CASNAV demonstra sua preocupação em verificar se as expectativas pessoais estão sendo satisfeitas pelos planos traçados pela organização. Isso se dá pelo fato de que essa satisfação está intimamente ligada à identificação dos indivíduos com os valores da organização. 
A afirmação anterior encontra respaldo em Gomes e Salas (1999, p.155) quando afirmam que:

a identificação refere-se à interiorização dos valores da organização por parte de seus membros e a sua transmissão no comportamento cotidiano. A identificação com a organização está muito ligada ao grau em que as expectativas pessoais sejam satisfeitas nos planos elaborados.

\section{Considerações finais}

O objetivo central do presente artigo foi o de verificar a relação, em termos de proximidade ou afastamento, entre o controle organizacional desenvolvido no CASNAV e os conceitos contidos na abordagem de Gomes e Salas (1999), no que se refere à perspectiva organizacional de controle. Para tanto, buscou-se, em primeiro lugar, o embasamento teórico necessário à compreensão do tema em lide, bem como a análise detalhada do desenho do sistema de controle gerencial do CASNAV sob o contexto organizacional.

Quanto ao objetivo específico, buscou identificar os mecanismos de controle gerencial adotados pelo CASNAV dentro do contexto organizacional, diante dos resultados obtidos pela referida organização, em especial do desempenho no PQGF.

Dos resultados encontrados, foi possível depreender que diversos mecanismos de controle utilizados se baseiam na identificação dos membros da organização com a cultura organizacional, fato este que confirma o pensamento de Gomes e Salas (1999, p.155) ao afirmarem que:

o desenvolvimento de uma cultura organizacional que promova a identificação das pessoas que fazem parte da organização pode possibilitar o aumento da coesão interna e, como consequência, atuar como mecanismo eficaz de controle de gestão, ao aumentar a probabilidade de que os comportamentos individual e organizacional sigam na mesma direção.

A ênfase dada pela alta administração do CASNAV no desenvolvimento de uma cultura interna voltada para a excelência, na qual a adoção de várias práticas, como a PCO, focada principalmente na qualidade de vida das pessoas, a implantação do SGQ, com destaque para os "promotores de qualidade" e um processo claro e eficaz de transmissão das informações demonstra a intenção de construir um ambiente em que haja uma probabilidade maior de ocorrência de comportamentos compatíveis com o desejado. Tal fato coaduna-se com Flamholtz (1979), pois o autor demonstra que os sistemas de controle são mais probabilísticos do que determinísticos, ou seja, o propósito é maximizar as condições favoráveis que levam ao goal congruence.

Com relação aos objetivos específicos, a participação anual no Prêmio Nacional de Gestão Pública do Governo Federal pode ser apontada como uma das formas encontradas pela alta administração do CASNAV para manter seus membros comprometidos com os objetivos organizacionais, configurando-se, dessa forma, em mecanismos de controle gerencial.

O uso intensivo de sistemas informatizados, destacando-se entre eles o Sistema de Gestão da Qualidade, também pode ser encarado como outra forma de controle gerencial utilizada, ressaltando ainda que, nesse caso, a organização apresenta uma vantagem, tendo em vista que muitos desses sistemas são desenvolvidos dentro do próprio CASNAV, ocasionando uma adequação destes ao contexto organizacional e cultural. Esse fato pode ser visto como um ponto positivo, pois se enquadra no pensamento de Hofstede (1981), quando afirma que antes 
de se usar um modelo para descrever ou analisar uma situação de controle, deve-se estudar cuidadosamente a natureza daquela situação para qual o modelo é apropriado. Assim, ao ter a capacidade de desenvolver seus próprios sistemas informatizados, o CASNAV aumenta a probabilidade de que esses sistemas atuem de maneira eficaz, uma vez que são desenvolvidos por pessoas que entendem, como ninguém, as necessidades organizacionais de controle.

No mesmo sentido, o sistema de avaliação global, baseado em indicadores de desempenho, configura-se em outro mecanismo de controle gerencial, possibilitando a consecução de metas, com resultados positivos relevantes, em uma situação em que, devido à impossibilidade da existência de sistemas de incentivos, principalmente os de caráter monetário, busca-se investir no fortalecimento da cultura organizacional, que, como se observou, foi identificada pela alta administração como fator diferencial capaz de mover as pessoas na direção pretendida, ficando patente o esforço envidado por parte da mesma em investir nos aspectos culturais dessa organização.

Diante do exposto, é possível sugerir uma proximidade entre as práticas de controle organizacional desenvolvidas pelo CASNAV e os conceitos contidos nas abordagens teóricas utilizadas, em especial na de Gomes e Salas (1999), sugerindo-se o desenvolvimento de novos estudos em organizações que se encontrem em situação semelhante, em termos de sistemas de controle gerencial, sejam públicas ou privadas, a fim de ratificar os resultados ora encontrados.

\section{Referências}

\section{ANTHONY, R. N. Planning and control}

systems: a framework for analysis. Boston: Harvard, 1965.

ANTHONY, R. N.; GOVINDARAJAN, V. Sistemas de controle gerencial. São Paulo: Atlas, 2002.

CASNAV - Centro de Análises de Sistemas Navais. Relatório de Gestão 2006. Rio de Janeiro, 2006.

FLAMHOLTZ, E. Organizational control systems as a managerial tool. California Management

Review, v. 22, n. 2, p. 50-59, 1979.

GIL, A.C. Como elaborar projetos de pesquisa.

3. ed. São Paulo: Atlas,1996.

GOMES, J. S. Um estudo exploratório sobre controle gerencial em empresas estatais brasileiras. 1983. 358 f. Tese (Doutorado em Administração) - Instituto COPPEAD de Administração, Universidade Federal do Rio de Janeiro, Rio de Janeiro, 1983.

GOMES, J. S.; RODRIGUES, A. Um estudo exploratório sobre controle gerencial em empresas brasileiras internacionalizadas do setor de serviçOs. In: ENCONTRO DA ASSOCIAÇÃO NACIONAL DOS PROGRAMAS DE PÓSGRADUAÇÃO EM ADMINISTRAÇÃO, 29., 2005, Curitiba. Anais... Curitiba: ANPAD, 2005. CD-ROM.

GOMES, J. S.; SALAS, J. M. Controle de gestão: uma abordagem contextual e organizacional. 2. ed. São Paulo: Atlas, 1999. 
HOFSTEDE, G. Management control of public and not-for-profit activities. Accounting, Organizations and Society, v. 6, n. 3, p. 193211, 1981.

KERLINGER, F. N. Metodologia da pesquisa em Ciências Sociais: um tratamento conceitual. São Paulo: EPU, 1980.

MARINHA DO BRASIL. Estado-Maior da Armada. EMA-137 - Doutrina de Liderança da Marinha. Brasília, DF, 2004a.

MARINHA DO BRASIL. Secretaria Geral da Marinha. SGM-301: normas sobre administração financeira e contabilidade, v. IV, 5. rev. Brasília, DF, 2004b.

MARTINEWSKI, A. L. Mudanças no controle gerencial de empresas brasileiras estatais e privatizadas: estudo de casos. 2003. $246 \mathrm{f}$. Tese (Doutorado em Administração) - Instituto COPPEAD de Administração - Universidade Federal do Rio de Janeiro, Rio de Janeiro, 2003.

MERCHANT, K. A. The control function of management. Sloan Management Review, v. 23, n. 4, p. 43-55, Summer 1982.

OTLEY, D. Management control in contemporary organizations: towards a wider framework.

Management Accounting Research, n. 5, p. 289-299, 1994.

OTLEY, D.; BROADBENT, J.; BERRY, A. Research in management control: an overview of its development. British Journal of Management, $\mathrm{v}$. 6, special issue, p. S31-S44, 1995.

PEREIRA, S. C. de S. O planejamento estratégico na Marinha do Brasil: o caso das Organizações Militares Prestadoras de Serviço (OMPS). Rio de Janeiro. 2006. 86 f. Dissertação (Mestrado em Administração Pública) - Escola Brasileira de Administração Pública e de Empresas (EBAPE) - Fundação Getúlio Vargas (FGV), Rio de Janeiro, 2006.

RICHARDSON, R. J. Pesquisa social: métodos e técnicas. 2. ed. São Paulo: Atlas, 1989.

SCHEIN, E. H.. Organizational culture and leadership. 2. ed. San Francisco: Jossey-Bass, 1992.
SMIRCICH, L. Concepts of culture and organizational analysis. Administrative Science Quarterly, n. 28, p 339-358, 1983.

SPILLER, E. S. O controle gerencial em empresas estatais brasileiras: o estudo do caso da CBTU. 1990. 244 f. Dissertação (Mestrado em Administração) - Instituto COPPEAD de Administração, Universidade Federal do Rio de Janeiro, Rio de Janeiro, 1990.

VERGARA, S. C. Projetos e relatórios de pesquisa em administração. 4. ed. São Paulo: Atlas, 2003.

YIN, Robert K. Estudo de caso: planejamento e métodos. 2. ed. Tradução de Daniel Grassi. Porto Alegre: Bookman, 2001. 